\title{
Population's willingness to separate collection of plastic waste in Russian city
}

\author{
Elena Rozhentsova $^{1,}{ }^{*}$, Anastasiia Saltykova $^{1}$, and Elena Tretiakova $^{2}$ \\ ${ }^{1}$ HSE University, Perm, Russia \\ ${ }^{2}$ Perm State National Research University, Perm, Russia
}

\begin{abstract}
This paper examines people's willingness to separate collection of plastic waste. The study is based on a questionnaire survey of Perm residents and visitors, the data were analyzed using econometric methods. We identified key factors that determine the ecological behavior of people - the importance for a person of the benefits that he carries for the environment, the willingness to devote personal time to measures to protect it and awareness of the environmental harm of plastic waste. On average, all things being equal, an individual's awareness of the environmental hazards of plastic leads to increase the probability of his participation in the separate collection of plastic by $11.78 \%$. On average, all things being equal, the proximity of containers for separate collection of plastic waste increases the probability that a person will participate in the separate collection of plastic by $45.57 \%$. It should be noted that the probability of participation in a separate collection is lower for men than for women, all things being equal. Also, all things being equal, the probability of participation in the separate collection of plastic increases with age by $0.3 \%$.
\end{abstract}

\section{Introduction}

Landfill waste deposition leads to the land elimination, pollution of soil, water bodies and emissions of harmful gases into the atmosphere. Russia is currently in the process of building a national system for collecting, sorting, processing and disposing of waste. The authors in this work analyzed the factors that determine the desire and readiness of people to separate the waste.

In previous studies, it is noted that the probability of a citizen's participation in environmental projects is influenced by demographic factors, external factors and internal factors (characteristic of an individual) [1] - gender [2,3], age [4,5], education [2,3,6], income (respondents with high income are more likely to have stated that they are willing to pay for environmental projects [4,5,6]), knowledge of the respondent about the environmental problem [2,6,7], concern about environmental problems (members of ecological groups and those who are increasingly concerned with environmental issues, are more likely to participate in recycling[8] and will be more willing to invest money into the implementation of environmental projects, if the project requires additional investments

*Corresponding author: aulita@yandex.ru 
$[3,9])$. An additional factor that affects exclusively the probability of a citizen's participation in separate garbage collection and disposal is the convenience of the garbage disposal process $[6,7]$.

Practical research in this paper focuses on the possibility of separate collection and disposal of plastic bottles (about half of all plastics are used in the production of disposable goods-packaging, etc.[10]). Based on previous studies, it can be assumed that the factors that determine people's willingness to sort plastic will be knowledge about the harm caused to the environment by harmful waste (in this study - plastic waste), and a person's personal civic position regarding environmentally responsible behavior (whether a person considers the benefits brought to the ecology of the country and the territory of their residence important for themselves). In addition, it is also worth considering the impact of basic social and demographic factors, such as gender, age, income, children, and higher education.

To assess the impact of these factors, the authors conducted a survey of respondents, and based on the data obtained, a logit model was built to identify factors that affect the readiness of citizens and guests of Perm to sort household garbage.

\section{Materials and Methods}

The data for the study were obtained in early 2019 by interviewing residents and guests of Perm over 18 years old.

In the survey, respondents were asked to rate on a scale from 0 to 9 the importance for them of the benefits they bring to the environment by doing separate garbage collection at the expense of their time ( 0 - time is more important; 9 - the benefits they bring to the environment are more important). The respondents were also asked to indicate whether they are aware of the environmental damage caused by the release of plastic waste into a common container and its subsequent placement in landfills ( 1 - yes, 0 - no). The respondents were also asked about their readiness to dispose of plastic bottles in special containers for separate collection of plastic waste. Moreover, some respondents indicated in the questionnaire that a special container for separate collection of plastic waste is located near the house (1). Some respondents in the questionnaire indicated that there are only a few plastic collection points in their city, and they are not located near your house (0). In addition, the questionnaire asked to indicate whether the respondent has minor children (1yes, 0 -no), whether the respondent has a higher education (1-yes, 0 -no), and asked to indicate their age, gender (1-male, 0 -female) and approximate monthly income per family member.

A total of 343 people (150 men and 193 women) aged 18 to 87 years took part in the survey. About $34 \%$ of the respondents have minor children. $49 \%$ of respondents have higher education. The average income per family member of the respondent is 26.61 thousand rubles. Descriptive statistics are given in Table 1.

Table 1. Descriptive statistics on the respondents of the questionnaire about the readiness of a person to conduct a separate collection of plastic

\begin{tabular}{|c|c|c|c|c|c|}
\hline Variables & Median & Mean & Min & Max & Stand. Dev. \\
\hline participation & 5 & 4.84 & 0 & 9 & 2.94 \\
\hline income & 20 & 26.61 & 3.5 & 120 & 17.27 \\
\hline
\end{tabular}

According to the survey data, $81 \%$ of respondents are aware of the dangers of plastic waste for the environment. On average, respondents claimed that they are more likely to benefit the environment (at the expense of their time) - about $58 \%$ of respondents chose categories from 5 to 9 , and $42 \%$ chose categories from 0 to 4 . In $50 \%$ of the questionnaires, it was indicated that the containers for plastic waste are located near their home, in the rest 
it was noted that the containers for plastic waste are not near the house.

To assess the willingness of people to participate in the separate collection of batteries, a regression logit model was constructed, where $\mathrm{Y}=1$ is the willingness of a person to collect and recycle plastic separately, and $Y=0$ is their unwillingness to participate in this process. The model describing the probability of people participating in a separate plastic collection is as follows:

$$
\operatorname{Logit}\left(P\left(Y=1 \mid x_{1}, \ldots, x_{n}\right)\right)=\beta_{0}+\beta_{1} x_{1}+\ldots+\beta_{n} x_{n}
$$

where, $\mathrm{x}_{1}, \ldots, \mathrm{x}_{\mathrm{n}}$ is a set of factors that affect the willingness to participate in the separate collection of plastic:

- participation - the importance of the benefits brought to the environment (at the expense of your time) (0-time is more important, 9-the benefits brought to the environment are more important)

- knowledge - awareness of the harm of plastic to the environment (the answer to the question "do you know what is the harm of the plastic waste release in general garbage?", yes - 1, no - 0)

- near the house - close location of containers for separate collection of plastic waste (the container is located near the house - 1 , not near the house - 0 )

- male - gender (men - 1, women - 0)

- age - age

- $\quad$ child - children under 18 years of age ( 1 - have children, 0 - no children)

- income - income

- education - availability of higher education,

and $\beta_{1}, \ldots, \beta_{\mathrm{n}}$. are the coefficients of the logistic regression of the corresponding factors. For these factors, the average marginal effects were calculated, and the quality of the model was evaluated.

\section{Results}

Out of 343 respondents, 239 respondents (93 men and 146 women) are ready to collect and dispose of plastic bottles separately, which is about $70 \%$ of all respondents. Moreover, the percentage of respondents who are ready to collect and dispose of plastic waste in a special container - who indicated in the questionnaire that the container is located near the house is $91 \%$, while only about $48 \%$ of respondents are ready to do this if the nearest container is not near the house (Fig. 1). 


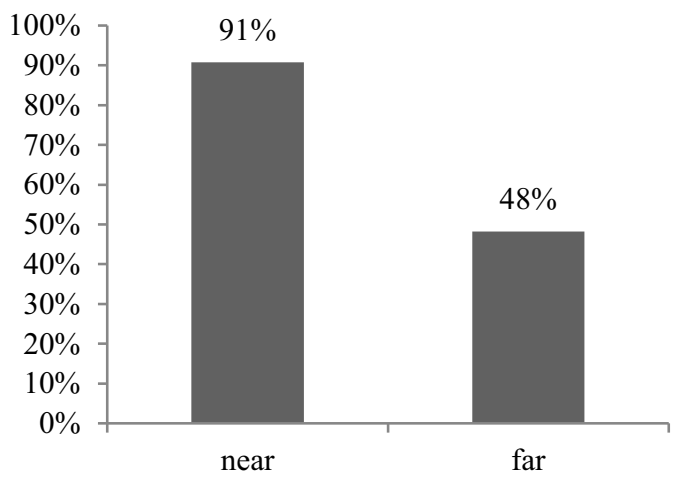

Fig. 1. The percentage of positive responses of respondents to the question about the readiness for separate collection and disposal of plastic waste, if the container is located near the house (near) and if the container is not near the house (far).

On average, women are more willing to do separate plastic collection than men: about $76 \%$ of women and about $62 \%$ of men are willing to do separate plastic collection (Fig. 2).

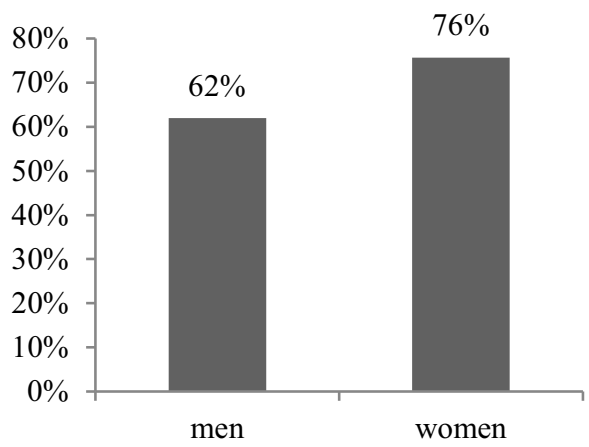

Fig. 2. The percentage of positive responses of respondents to the question about their readiness for separate collection and disposal of plastic waste in the gender context.

Respondents aged 35 to 54 years are more willing to collect and dispose of plastic bottles separately (Fig. 3).

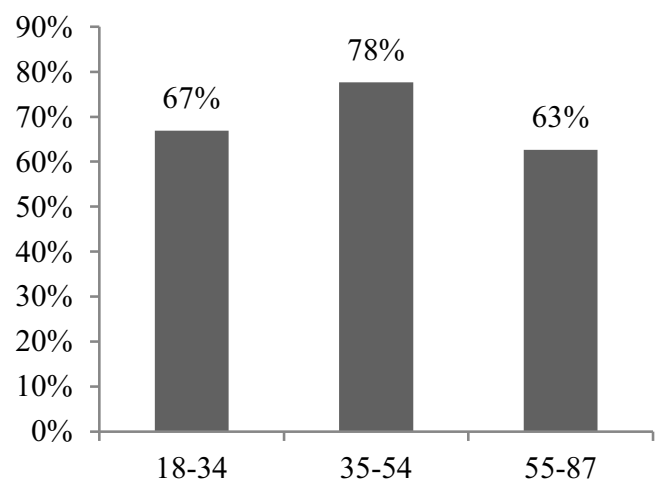

Fig. 3. The percentage of positive responses of respondents to the question about their readiness for separate collection and disposal of plastic waste by age group. 
$73 \%$ of the respondents who are aware of the dangers of plastic waste for the environment are ready to carry out separate collection and disposal of plastic waste. Among those who are not aware of the harm of plastic to the environment, $58 \%$ of respondents are ready for separate sorting of plastic (Fig. 4).

In general, people who are more interested in the benefits they bring to the environment (at the expense of their time) are more willing to separate sorting and recycling of plastic waste. Among the respondents who rated their importance of use as medium/high (by 5-9 points), $77 \%$ are ready for separate garbage collection. Among the respondents who rated their importance of the benefit as a low one (by $0-4$ points), about $60 \%$ of respondents are ready for this (Fig. 5).



Fig. 4. The percentage of positive responses of respondents to the question about readiness for separate collection and disposal of plastic waste, if respondents know about the harm of plastic to the environment (know)/do not know about it (don't know).

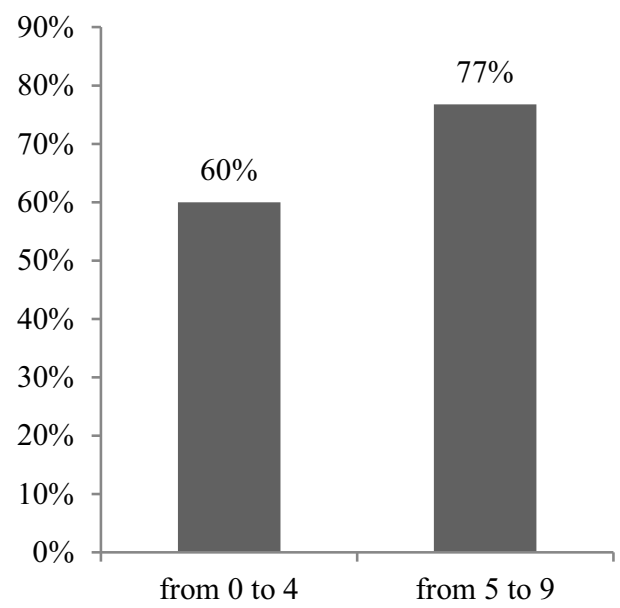

Fig. 5. The percentage of positive answers to the question about readiness for separate collection and recycling of plastic waste, if respondents are more important to them than the benefit that they bring to the environment (from 0 to 4 ) and if the respondents are more important benefit that they bring the environment to the detriment of their time (from 5 to 9 ). 
The results of the logit model evaluated by the maximum likelihood method, presented in Table 2, show that a statistically significant influence on a person's readiness to participate in the separate collection of plastic is the importance of the benefits they bring to the environment (at the expense of their time), awareness of the environmental harm of plastic, the proximity of tanks for separate collection of plastic waste, as well as the gender and age of the respondent. The presence of children, the availability of higher education and the level of income were statistically insignificant.

Table 2. Results of the regression logit model for the readiness of a person to conduct a separate plastic collection.

\begin{tabular}{|c|c|c|}
\hline & Coefficient regression & Average marginal effects \\
\hline const & -0.3179 & 0.0308 \\
\hline participation & $0.1770^{* * *}$ & 0.1178 \\
\hline knowledge & $0.6157^{*}$ & 0.4557 \\
\hline near the house & $2.6801^{* * *}$ & -0.0912 \\
\hline male & $-0.5158^{*}$ & -0.0030 \\
\hline age & $-0.0174^{*}$ & -0.0227 \\
\hline child & -0.1290 & -0.0014 \\
\hline income & -0.0080 & 0.0209 \\
\hline education & 0.1201 & \\
\hline McFadden's Pseudo $\mathrm{R}^{2}$ & 0.26 & \\
\hline $\mathrm{R}^{2}$ adjusted & 0.22 & \\
\hline Log-likelihood & -155.26 & \\
\hline Likelihood-ratio chi- & $109.66 * * *$ & \\
\hline squared test & 342 & \\
\hline Number of observation & & \\
\hline
\end{tabular}

Note: $* * *, * *, *$ indicate significance at the $1 \%, 5 \%$, and $10 \%$ levels, respectively.

On average, all other things being equal, each additional unit in the rating scale from the absolute importance of personal time (0) to the absolute importance of the benefits to the environment at the expense of their own time (9) will increase the probability that a person will participate in the separate collection of plastic by $3.08 \%$. On average, all other things being equal, an individual's awareness of the environmental hazards of plastic leads to an $11.78 \%$ increase in the probability of their participation in the separate collection of plastic. On average, all other things being equal, the proximity of tanks for separate collection of plastic waste will increase the probability that a person will participate in the separate collection of plastic by $45.57 \%$. It should be noted that the probability of participation in a separate collection for men on average, all other things being equal, is $9.12 \%$ lower than for women. Also, an increase in an individual age leads to a decrease in the probability of his participation in the separate collection of plastic by $0.3 \%$. The quality of the binary choice model was evaluated using McFadden's Pseudo $\mathrm{R}^{2}$, which was 0.26. Also, based on the results of the significance of $\mathrm{x}^{2}$ statistics, we can say that the model is statistically significant at the significance level of $1 \%$. This model allows us to correctly predict 249 positive responses from respondents about their readiness to sort plastic waste, which is $72.8 \%$ of the total number of respondents.

The results of the logit model evaluated by the maximum likelihood method, given in Table 3, indicate that a statistically significant influence on a person's readiness to participate in the separate collection of plastic (provided that plastic containers are in close proximity) has the importance for him of the benefits he brings to the environment, as well as awareness of the environmental harm of plastic. Factors such as gender, age, having children, having a higher education, and income level were found to be statistically insignificant. 
Table 3. Results of the regression logit model for the readiness of a person to carry out a separate collection of plastic, if the containers were outside the house.

\begin{tabular}{|c|c|c|}
\hline & Coefficient regression & Average marginal effects \\
\hline const & 1.5535 & \\
\hline participation & $0.0043^{* * *}$ & 0.0117 \\
\hline knowledge & $1.4793^{* *}$ & 0.0666 \\
\hline male & -0.7260 & -0.0221 \\
\hline age & -0.0179 & -0.0005 \\
\hline child & 1.2352 & 0.0326 \\
\hline income & -0.0212 & -0.0006 \\
\hline education & -0.2447 & -0.0070 \\
\hline McFadden's Pseudo $\mathrm{R}^{2}$ & 0.35 & \\
\hline $\mathrm{R}^{2}$ adjusted & 0.20 & \\
\hline Log-likelihood & -34.67 & \\
\hline $\begin{array}{c}\text { Likelihood-ratio chi- } \\
\text { squared test }\end{array}$ & $37.13 * * *$ & \\
\hline Number of observation & 172 & \\
\hline
\end{tabular}

Note: $* * *, * *, *$ indicate significance at the $1 \%, 5 \%$, and $10 \%$ levels, respectively.

On average, all other things being equal, each additional unit in the rating scale from the absolute importance of personal time (0) to the absolute importance of the benefit to the environment at the expense of their own time (9) will increase the probability that a person will participate in the separate collection of plastic by $1.17 \%$, provided that the tanks are close to the respondent's home. On average, all other things being equal, an increase in an individual's awareness of the environmental hazards of plastic, provided that the tanks are close to the respondent's home, leads to an increase in the probability of their participation in the separate collection of plastic by $6.66 \%$. The quality of the binary choice model was evaluated using McFadden's Pseudo $\mathrm{R}^{2}$, which was 0.35 . The model is statistically significant at a significance level of $1 \%$. This model allows us to correctly predict 160 positive responses from respondents about their readiness to sort plastic waste, provided that the tanks are close to the house, which is $93 \%$ of the total number of respondents, provided that the containers are nearby.

The logit model evaluated by the maximum likelihood method, which examines the influence of various factors on a person's readiness to participate in the separate collection of plastic bottles (if the plastic containers are not located near the house), was not statistically significant. The results of the regression model for a person's readiness to participate in the separate collection of plastic (if plastic containers are not near the house) with the only significant factor from that model - the importance of environmental benefits - are presented in Table 4.

Table 4. The results of the regression logit model for the willingness of a person to carry out a separate collection of plastic, if the containers were not near the house, with the factor of importance of the benefits brought to the environment.

\begin{tabular}{|c|c|c|}
\hline & Coefficient regression & Average marginal effects \\
\hline const & $-0.6974^{* *}$ & \\
\hline participation & $0.1337^{* *}$ & 0.0334 \\
\hline McFadden's Pseudo $\mathrm{R}^{2}$ & 0.03 & \\
\hline $\mathrm{R}^{2}$ adjusted & 0.01 & \\
\hline Log-likelihood & -114.66 & \\
\hline Likelihood-ratio chi-squared test & $6.14^{* *}$ & \\
\hline Number of observation & 170 & \\
\hline
\end{tabular}

Note: $* * * * *, *$ indicate significance at the $1 \%, 5 \%$, and $10 \%$ levels, respectively. 
The last built model shows the following. On average, all other things being equal, each additional unit in the rating scale from the absolute importance of personal time ( 0 ) to the absolute importance of the benefit to the environment at the expense of their own time (9) will increase the probability of human participation in the separate collection of plastic (in the case when plastic containers are not near the house) by $3.34 \%$. The quality of the binary choice model was evaluated using McFadden's Pseudo $\mathrm{R}^{2}$, which was 0.03 , the model is statistically significant at a significance level of $5 \%$. This model allows us to correctly predict 97 positive responses of respondents about their readiness to sort plastic waste if plastic containers are not near the house, which is $57.1 \%$ of the total number of respondents provided that the containers are not near the house.

$91 \%$ of respondents said they would throw plastic bottles into a special plastic container outside their houses. Thus, we can conclude that even if every house in Perm is equipped with a special tank (as long as they are not equipped), about $9 \%$ of the population over the age of 18 will not throw plastic bottles in a special plastic container. 52\% of respondents said that they would not throw plastic bottles in a special tank that is not near the house. That is, even if there are several special containers intended for plastic waste in the city, and citizens will know where these containers are, still a high percentage of the population will not throw them away separately. In this case, both the ecology of the region and the production of waste processing, which will receive less raw materials, suffer.

It is important that the study revealed two significant factors that affect the readiness to sort and dispose of plastic waste in containers intended for them, the values of which can be influenced and thereby increase the percentage of plastic waste in special tanks. The first factor is the importance of the benefits that a person brings to the environment at the expense of his time. The second factor is the factor of knowledge about the dangers of discarding plastic bottles together with other garbage. The first factor can be influenced by mass propaganda of the importance for a person of the benefits that he brings to the environment, sacrificing his time (the population should feel positive emotions from participating in environmental projects, from their involvement in careful consumption, understand the importance of their actions to protect the environment, etc.). Such propaganda is likely to not only encourage more plastic collection, but also generally encourage more public participation in other environmental projects. The second factor can be influenced by environmental education, in particular by explaining the harm of discarding plastic together with other garbage. The graph of respondents ' awareness of the dangers of co-dumping plastic with other garbage shows that citizens aged 45-54 are the most knowledgeable (Fig. 6). At a younger age, the percentage of knowledge is slightly lower, which is probably due to the lower amount of accumulated knowledge. And older people (after 55 years) probably have less knowledge about the dangers of co-dumping plastic with other garbage due to the fact that this problem was not actively discussed in their childhood and youth. No age group has knowledge higher than $90 \%$, so we believe that it is necessary to talk about the dangers of joint waste disposal to a wide audience, paying special attention to younger and older citizens. 


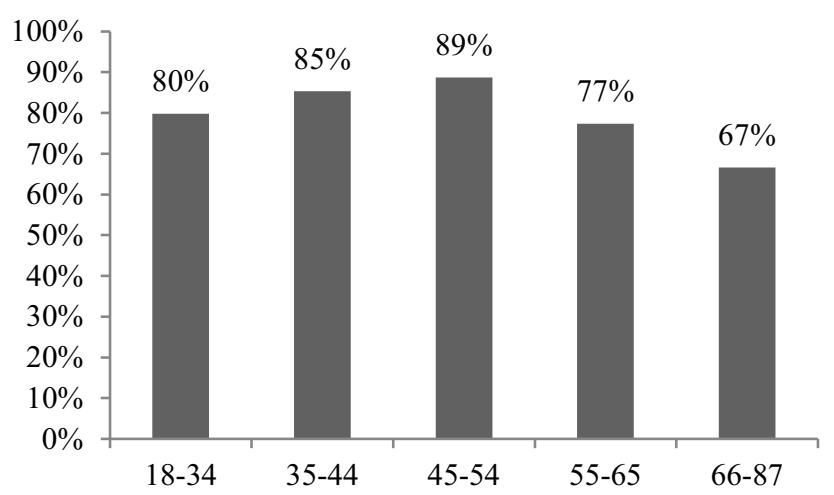

Fig. 6. The percentage of positive responses of respondents to the question about the knowledge about the harm of plastic waste to the environment by age group.

The average score of respondents on the question of the importance of environmental benefits by age group is estimated below (Fig. 7).

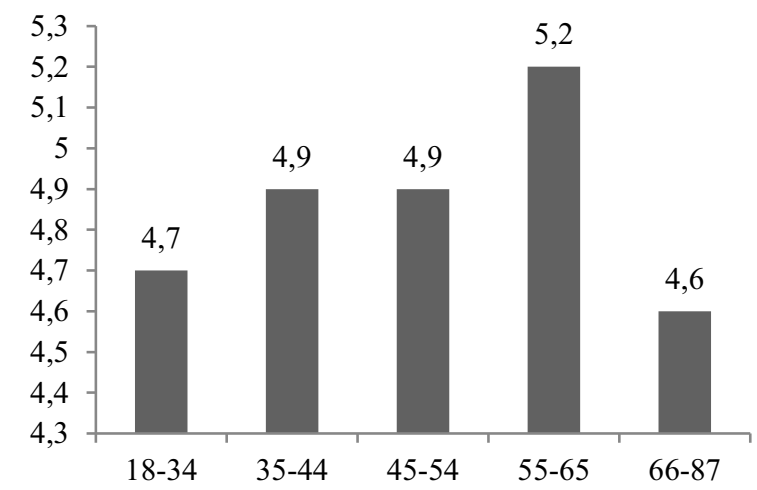

Fig. 7. The average score of respondents to the question about the importance of the benefits brought to the environment at the expense of their time by age group.

Given that the average score of respondents on the question of the importance of the benefits brought to the environment (at the expense of their time) does not differ much in all age groups, and in all but one group below 5, it is necessary to promote proenvironmental behavior of different age groups.

\section{Discussion}

Similarly to the previous studies, our work confirmed their influence on the probability of participation of the Respondent in the environmental event (in our study - willingness to participate in plastic sorting) factor of awareness of respondents about the environmental problem $^{[2,7,9]}$ and a factor of importance in Respondent's participation in environmental issues (members of ecological groups and those who are increasingly concerned with environmental issues, are more likely to participate in environmental projects (and in particular in the garbage sorting ${ }^{[8]}$ ) and would be willing to invest more money in the implementation of environmental projects, if the project requires additional investments $^{[3,9]}$.

Also, the findings of our study are consistent with previous studies, in which it was 
proved that older respondents are less likely to participate in environmental projects compared to younger respondents ${ }^{[4,5]}$. The convenience of the garbage disposal process the presence of special tanks close to the house-is an important factor in achieving better results in separate garbage collection ${ }^{[6,7]}$. Moreover, a study conducted in China found that the option of throwing waste (for example, batteries) into containers at home was preferable to even collecting batteries at the door or in the supermarket ${ }^{[8]}$.

In the previous works, as in our work, the influence of gender on the probability of citizens ' participation in environmental projects is proved, but in the previous works, the result was the opposite of ours - in India and Sweden, men are more likely than women to participate in environmental activities and are more willing to pay for them ${ }^{[2,3]}$.

The study conducted in this article showed that the population is not fully ready to sort garbage at the present time. You can offer a variety of options to encourage the population to separate collection and disposal of garbage - the installation of containers for separate collection of waste near houses, environmental propaganda, environmental education. On the one hand, their effect is not obvious, on the other hand, they all require costs for their implementation. Therefore, it is important to understand the effect that they will bring. The results obtained in the above study indicate that the most important factor that significantly affects the probability of separate collection of garbage by respondents is the availability of containers for separate collection of garbage at home. The presence of a plastic waste container at home increases the probability of separate collection of plastic bottles by an average of about $46 \%$. But placing containers at each house is an expensive way to increase the volume of separate garbage collection, which is not achievable in the near future in Perm - in the city where the study was conducted. Therefore, in order to influence the process of separate collection and disposal of garbage, it is necessary to promote environmental awareness in the direction of establishing a sense of the importance of participation in environmental projects, as well as environmental education - increasing the level of public knowledge about the dangers of joint garbage collection. As the analysis conducted in the article showed, the importance for a person of the benefits they bring to the environment (to the detriment of their time) will increase the likelihood of separate collection and disposal of garbage, even if the tank is not near the house.

Further research is planned to be devoted to calculating the costs of steps aimed at encouraging separate garbage collection and their correlation with the resulting effects, as well as studying and understanding the issues that need to be addressed in the framework of environmental education. A comprehensive analysis of the issue under study will allow us to more accurately develop steps to achieve maximum participation of citizens in environmental projects, which, at a certain level of costs, brought the maximum effect in achieving the set result.

\section{Conclusion}

A person's willingness to participate in the separate collection of plastic is influenced by the importance for them of the benefits they bring to the environment (at the expense of their time), awareness of the environmental harm of plastic, the proximity of containers for separate collection of plastic waste, as well as the gender and age of the person. On average, men are less likely to participate in a separate collection than women. There is also some reason to believe that an increase in the age of an individual leads to a decrease in the probability of his/her participation in the separate collection of plastic.

The willingness of a person to participate in the separate collection of plastic (provided that the plastic containers are close to the house) is influenced by two factors: the degree of importance of the benefits brought by a person to the environment, and the awareness of the individual about the harm of plastic to the environment. 
The willingness of a person to participate in the separate collection of plastic (if the plastic containers are not located near the house) is affected by the importance of the benefits they bring to the environment.

\section{References}

1. A. Kollmuss, J. Agyeman, Environmental Education Research 8, 239-260 (2002) DOI: 10.1080/13504620220145401

2. D. Rajapaksa, M. Islam, S. Managi, Sustainability 10(4), 937 (2018) DOI: $10.3390 /$ su10040937

3. F. Carlsson, O. Johansson-Stenmann, Applied Economics 32, 661-669 (2000) DOI: $10.1080 / 000368400322273$

4. F. Gordillo, P. Elsasser, S. Günter, Forest Policy and Economics 105, 28-39 (2019) DOI:10.1016/J.FORPOL.2019.05.002

5. X. Liu, G. Pan, Y. Wang, et al., Journal of Coastal Research 74, 207-213 (2016) DOI: 10.2112/SI74-018

6. Q. Song, Z. Wang, J. Li, Journal of Environmental Management 106, 8-16 (2012) DOI: 10.1016/j.jenvman.2012.03.036

7. T.P. Wagner, P. Toews, R. Bouvier, Journal of Environmental Management 123, 88-97 (2013) DOI: 10.1016/j.jenvman.2013.03.020

8. M. Sun, X. Yang, D. Huisingh et al., Journal of Cleaner Production 107, 775-785 (2015) DOI: 10.1016/j.jclepro.2015.05.081

9. J. Loomis, P. Kent, L. Strange et al., Ecological Economics 33, 103-117 (2000) https://doi.org/10.1016/S0921-8009(99)00131-7

10. J. Hopewell, R. Dvorak, E. Kosior, Phil. Trans. R. Soc. B. 364(1526), 2115-2126 (2009) 